\title{
Efficiency in Foundation Provisioning in a Selected University
}

\author{
Dr Vuyisile Nkonki \\ University of Fort Hare, VNkonki@ufh.ac.za
}

Ms Siyanda Ntlabathi

University of Fort Hare, SNtlabathi@ufh.ac.za

Mrs Thobeka Ncanywa

University of Fort Hare, TNcanywa@ufh.ac.za

\section{Doi:10.5901/mjss.2014.v5n11p57}

\section{Abstract}

Foundation Provisioning is defined as the provisioning of modules, courses or other curricular elements that are intended to equip underprepared students with academic foundations that will enable them to successfully complete a higher education qualification. The models adopted for these subsidised programmes allow for more time, more teaching, learning and assessment opportunities for students, and expend more resources than their mainstream counterparts. This paper sought to measure the efficiency of programmes, Faculties, and the institution, and to determine the predictors of efficiency in Foundation Provisioning in a selected university. It also sought to establish whether foundation provisioning efficiency has a bearing on mainstream academic success. Framed in the positivist perspective and the ex post facto design, secondary data was obtained on a cohort of foundation students. This research looked into the mainstream achievement results for these foundation students at the end of the third year of study in four Faculties with foundation programmes. The input data included foundation training workshops for lecturers, Supplemental Instruction (SI) for foundation modules, average salaries for foundation lecturers, and the Faculties' years of experience in running foundation programmes. The output data were the module pass and completion rates in the third year of study. The efficiencies of foundation programmes in the entire university were analysed using Data Envelopment Analysis (DEA) models. Regression was used to determine factors that predict and impact on the efficiency levels, while linear prediction was used to determine whether efficiency explains success in the mainstream. The overall efficiency of Foundation Provisioning in a selected historically disadvantaged university is reported. The paper then proceeds to describe significant differences in the efficiencies of various programmes in the Faculties, and the predictor variables that explain the efficiencies of programmes within this selected university. Lastly, this paper reports on whether foundation provisioning efficiency has a bearing on academic success in the mainstream. The study concludes that there are variations in the efficiency levels of faculties and programmes and these are accounted for by the salary levels of foundation lecturers as well as the Faculty's experiences of running foundation provisioning. At practice level, in the Faculties and programmes, the study recommends improvement of efficiency levels of programmes by altering the input variables.

Keywords: foundation provisioning, efficiency, academic success, data envelopment analysis

\section{Introduction}

This study is done at a South African Higher Education Institution (HEI) which introduced Foundation Provisioning (FP) programmes in four of its Faculties to under-prepared students who gained formal access in Higher Education institutions. Foundation provisioning is defined as the offering of modules, courses or other curricular elements that are intended to equip under-prepared students with academic foundations that will enable them to successfully complete a higher education qualification. Foundation programmes are state subsidized programmes intended to assist underprepared students to cope with the demands of mainstream academic programmes (Department of Education, 2001). Foundation programmes focus particularly on basic concepts, content and learning approaches that foster advanced learning. Foundation Provisioning aims at enabling epistemological access which involves making overt disciplinary rules and conventions, as well as making implicit academic practices and knowledge systems more explicit (Boughey, 2005; Frith an Lloyd, 2013).

Foundation provisioning came about as a National Imperative strategy on Higher Education Institutions to improve 
student success and throughput rates. Success and throughput rates are some of the key critical challenges facing Higher Education Institutions (Strydom, Mentz and Kuh, 2010). According to Strydom, Mentz and Kuh, (2010) these challenges arose due to massification in Higher Education institutions. Massification led to unprecedented levels of diversity and many first generation students accessing higher education. As a result very low pass rates and high dropout rates are experienced. Foundation Provisioning is a strategy for addressing inequality and equity issues in Higher Education. Foundation provisioning is motivated by the social and educational justice imperative that all students should be assured epistemological access and academic success.

What needed to be addressed was the articulation gap between what first year entering students bring and the expectations of Higher Education Institutions (Scott, Yeld, and Hendry, 2007). The nature of the articulation gap range from: (1) content and conceptual development; (2) approaches to learning; (3) academic language and, (4) affective factors which include poverty, large class scenario, independence and many others (Scott, et al, 2007). Research by Higher Education South Africa (HESA) reports that 35\% of the first years drops out after their first year of study (SAPA, 2008). Breier and Mabizela (2007) found that only $15 \%$ of students, who enroll, complete their degree in the designated time. They point out that $30 \%$ dropout after the first year, and that a further $20 \%$ drop out after their second and third years of study.

Foundation programmes are structured differently from mainstream programmes. As defined by the South African Department of Education (2001) above, they are structured such that they allow for more engagement time, and hence most of them are referred to as extended programmes. What mainstream students would do over a semester is stretched over a year for foundation students. The figure below shows the difference between foundation/extended programmes and mainstream programmes as conceptualised and developed by the authors of this paper.

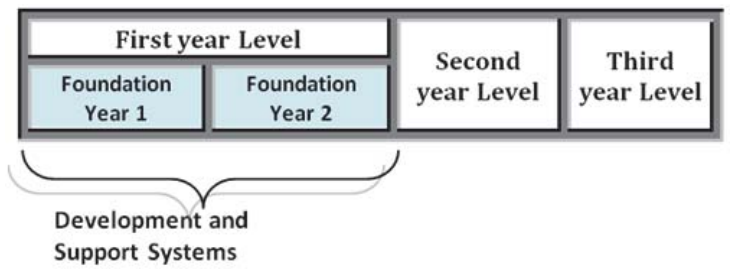

Figure 1: Structural representation of Foundation versus Mainstream

The South African government has prioritised education as number one on its expenditures (Budget Speech, 2013). Universities are important institutions within the education system that provide government programmes that will improve efficiency in the whole country. Universities are important to the proper functioning of an economy at both micro and macro level. At micro-level, universities need to achieve both technical and allocative efficiency. Technical efficiency captures the relationship between input utilization and output attainment. Allocative efficiency captures the input combination that is chosen given the input prices (Giminez, Prior, and Thieme, 2007).

Universities should be committed to the efficient use of public funds, and continually seek opportunities to enhance productivity and use fewer resources in order to ensure maximum utilisation of public funds for the benefit of the high quality programs provided to students. Giminez, Prior and Thieme (2007) point out that educational productivity measures whether the resources allocated to education are being used effectively. There has been a growing interest in recent years in evaluating the efficiency of education institutions, especially those operating in the public sector (Mancebon and Bandres, 1999; Badri and Mourad, 2012).

This research sought to measure the overall efficiency of Foundation Provisioning in a selected university, determine the efficiencies of programmes within the Faculties, and establish predictor variables that explain the efficiency of programmes and Faculties within this selected university.

\section{Efficiency in Education}

Cooze (1991) defines efficiency as the relationship between inputs and outputs, with economic efficiency defined as gain in units of output per unit of input. Tattersal, Waterink, Hoppener, and Koper (2006) cite the United Nations' Educational Scientific and Cultural Organisation's (UNESCO's) definition of educational efficiency as the degree to which educational systems are successful in optimising the educational input/output relationship. Since educational systems have no single defined function, there are no single well defined indicators of output. It stands to reason, therefore, that various 
educational outcomes can result from a variety of different combinations of inputs. The synthesis of several studies on the measurement of education production suggests that academic performance; skills, attributes and values that favour workplace and social integration; communication and interpersonal skills, respect for the environment, physical fitness; and political, social and personal responsibility, teachers, buildings, class size, curriculum, et cetera are indicators of the education production function (Gray, 1981; Ray, 1991; Thanassoulis and Dunstan, 1994; Rico, 1996; Silva-Portela and Thanas soulis, 2001). However, looking at the complexity of some of the factors that constitute the educational production function, the majority of existing studies mainly concentrate on academic performance.

The challenge for both educators and economists is how to mix inputs in right proportions so as to achieve educational outcomes in the most efficient manner. The other challenge concerns the output that we should measure. Perelman and Santin (2011) put forward some of the reasons why empirical research does not find systematic relationships between school inputs and outputs. They argue that "education is a highly complex process with variables, such as organisation or non-monetary inputs, implied in production". Efficiency measures consider education as a process in which students use their own and school inputs in order to transform these inputs into academic results. The extent of efficiency in the school or programme is also dependent on behaviours of all the parties involved that can be identified at both student and school levels. Carter (2012) identifies some of the variables that are normally included in the study of educational efficiency. The input variables include teacher: student ratio, teachers' average years of experience, teachers' qualifications, and the average base salary. The outcomes variables are grades, drop-out rates, failure rates, and through-put rates. Other variables that are normally used include student enrolment figures, students' racial groupings, and the socio-economic status of the students.

When educational outputs are confined to academic success or achievement, educational efficiency, then, becomes the ratio of the number of learners successfully completing all the required units of learning associated with the goal (numerator) to the number of learners starting down the path towards the goal (denominator) within a given period (Tattersal, Waterink, Hoppener, and Koper, 2006). Whilst acknowledging the limitations of measuring efficiency in education, educational efficiency data is used to allocate funds to learning providers. Efficiency data could also be used to provide evidence of the success or otherwise failure of the educational interventions. It is also a useful measure of the quality of educational processes. Levin, et al (1976) argue further that efficiency measures provide an account of resource allocations and usage, as well as the formulation of decisions and rules for improving the effectiveness in the manner in which resources are used at institutional and programme levels of the education sector.

\section{Statement of the Problem}

This research sought to describe the institutional overall efficiency, faculty efficiencies, as well as efficiencies at programme levels in the provisioning of foundation programmes. It also sought to compare efficiencies, determine predictors of efficiencies from the input variables used, and determine the bearing that efficiency in foundation provisioning has on academic success in the mainstream.

\section{Objectives of the Study}

1. To estimate the efficiency of Foundation Provisioning in a selected university.

2. To establish significant differences in the efficiencies of Faculties running Foundation Provisioning in a selected university.

3. To establish significant differences in the efficiencies of Foundation Provisioning programmes in a selected university.

4. To determine the predictors of efficiency in Foundation Provisioning programmes of the various Faculties in a selected university.

5. To establish the link between efficiency in foundation provisioning and academic success in the mainstream.

\section{Research Methodology}

\subsection{Research paradigm}

This study employed the positivist perspective which views knowledge as structured interconnections between variables formulated as hypotheses (Gephart, 1999; Cohen, Manion, and Lawrence, 2007)). These hypotheses have a predictive power which enables the researcher to anticipate what the situation will be like. Hypotheses help the researcher to 
identify trends and patterns, provide the basis for prediction, which provides the basis for control. Based on these predictions, rules for action are formulated, and ways of altering and managing situations are devised (Gepahrt, 1999; Mackenzie and Knipe, 2006; Cohen, Manion, and Lawrence, 2007). The paradigm was selected for its appropriateness in identifying efficiencies, determining the predictors of efficiency, and drawing connections between efficiency and academic success. The findings would then form the basis for decisions around the management and better utilisation of resources in foundation provisioning.

\subsection{Research Design}

An exp post facto design was used by the researchers since the study involved secondary data, and the examination of this pre-existing data retrospectively to establish relationships or associations (Cohen, Manion, and Lawrence, 2007) between input variables and output variables in foundation provisioning. For both the input and output variables secondary data was examined retrospectively to determine the effects on efficiency, the predictors of effeiciency, as well as the association between foundation provisioning efficiency and mainstream academic achievement.

\subsection{Population and sampling}

For this particular study, the sample consisted of all the Foundation students registered in 2010 in four Faculties of a university. The input side of the efficiency ratio consisted of all the students enrolled for the Foundation Provisioning programmes, namely: B.A.; B.Admin; B.Agric; B.Comm; B.SocSc; BTheol; B.Comm (Acc); B.Sc; B.Sc (Agric); and LLB in 2010. In a programme, learner progression is measured in traditional, restricted, cohort-based situations. This particular research focused on the 2010 foundation cohort of students who would have reached mainstream in 2012 for their $2^{\text {nd }}$ year mainstream courses/modules. The end dates for reaching the programme's goal were set as 2012, which reflects academic achievement of this cohort in the first year of mainstream. Though 2012 is not the end date for completing the programmes, it is a useful end point since the 2012 academic achievement results should be a reflection of the foundations laid in the two years of foundation provisioning. The period over which efficiency is measured is therefore, 3 years.

\subsection{Data Collection}

The input data included attendance and participation by foundation lecturers in the Foundation Provisioning training workshops. This data was obtained from the foundation provisioning co-ordinator, an academic development practitioner in the academic development centre. Data on the Foundation Provisioning modules and students supported by Supplemental Instruction (SI) was also obtained from the quarterly reports of the academic development centre. Data on the salaries of Foundation Provisioning lecturers was obtained from the co-ordinators of Foundation programmes in the Faculties. The Faculties' years of experience in running Foundation Provisioning were furnished by the Foundation coordinators. The output data were 2010-2012 pass and completion rates which were obtained from the university's Higher Education Management Information Systems (HEMIS) officer.

\subsection{Data analyses}

Due to the fact that in a university environment, it is easier to control the inputs rather than the outputs, the Data Envelopment Analysis (DEA) input oriented model was used to compute the efficiency of the programmes and Faculties. The efficiencies in the table below were deemed the most relevant for the study and are calculated, reported and discussed in the paragraphs below.

Table 1: Efficiency Measures

\begin{tabular}{|l|}
\hline TFP - Total Factor Productivity \\
\hline TFP* - Maximum possible TFP \\
\hline TFPE - TFP efficiency \\
\hline OTE - output-based technical efficiency \\
\hline OSE - output-based scale efficiency \\
\hline ITE - input based technical efficiency \\
\hline ISE - input-based scale efficiency \\
\hline
\end{tabular}


To determine the efficiencies of programmes, Total Factor Productivity (TFP) was used to show maximum possible productivity. In addition, Total Factor Productivity Efficiency (TFPE) was used to compute the levels of efficiency. The TFPE determines the extent to which the productivity of a programme approximates the maximum possible productivity in relation to the inputs available for a given period (Perelman and Santin, 2008; Carter, 2012; Giminez, Prior, Thieme, 2007). Also, regression analysis was used to identify factors that predict and impact on Foundation Provisioning (FP) efficiency levels. In order to establish whether Foundation Provisioning efficiency explains success in the mainstream prediction analysis was conducted. The findings from these analyses are presented in the paragraphs below.

\section{Findings}

\subsection{The overall efficiency of Foundation Provisioning.}

The efficiency score (TFPE) of university as a whole for foundation programs is 0.43826 , which indicates an inefficient gap of over $56 \%$. The greater portion of the efficiency is from the output side (OTE= 0.9 ) as compared to the input based (ITE=0.6). Given the nature of our data, it is imperative to scale and drill down to the Faculties then programmes so as to get a clearer understanding of where the efficiencies and inefficiencies are, in foundation provisioning for this selected university.

\subsection{Significant differences in the efficiencies of Faculties with Foundation Provisioning.}

The findings in figure 2 below, suggest that the Faculty of Law performs well across different forms of efficiencies, both from the output-based and input-based models (TFPE $=0.67$ ). The Faculty of Management and Commerce is the least efficient (TFPE= 0.2) only outperforming Science and Agriculture in output based technical efficiency.

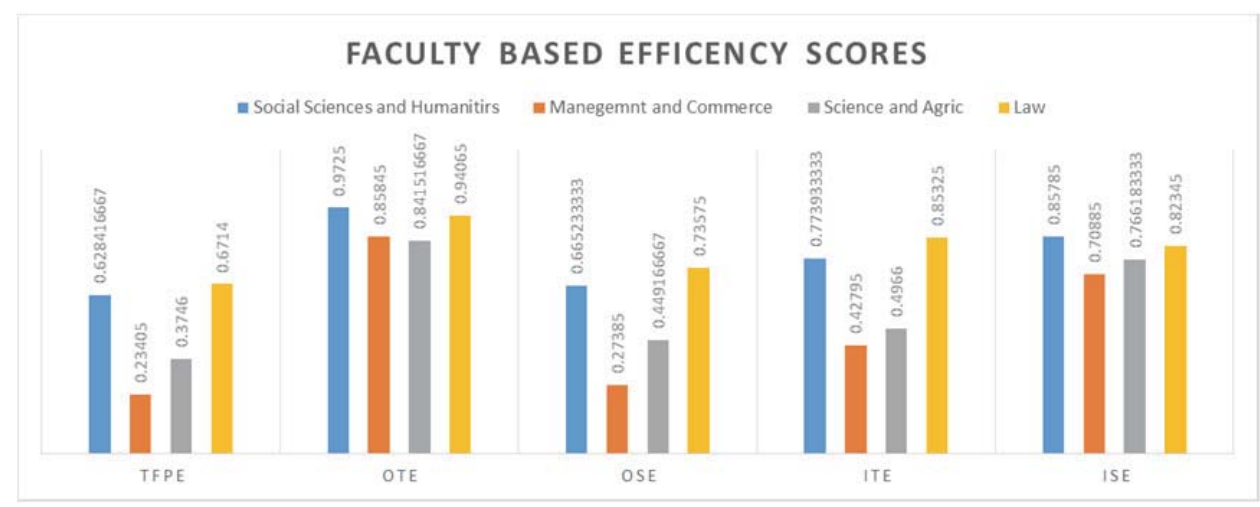

Figure 2: Foundation Provisioning Efficiencies of Faculties

\subsection{Significant differences in the efficiencies of Foundation Provisioning programmes.}

To meet this objective various efficiency scores of all programmes offering foundation provisioning were calculated using the DPIN (Decomposing Productivity Index Numbers) software. The calculation is from the productivity indexes and the key variable is the total factor productivity efficiency (TFPE). The TFPE in essence is a measure of overall productive performance. The Total Factor Productivity Efficiency (TFPE) in figure 3, below, shows the levels of efficiency of the various programmes with foundation provisioning for the 2010 and 2011 academic years. 


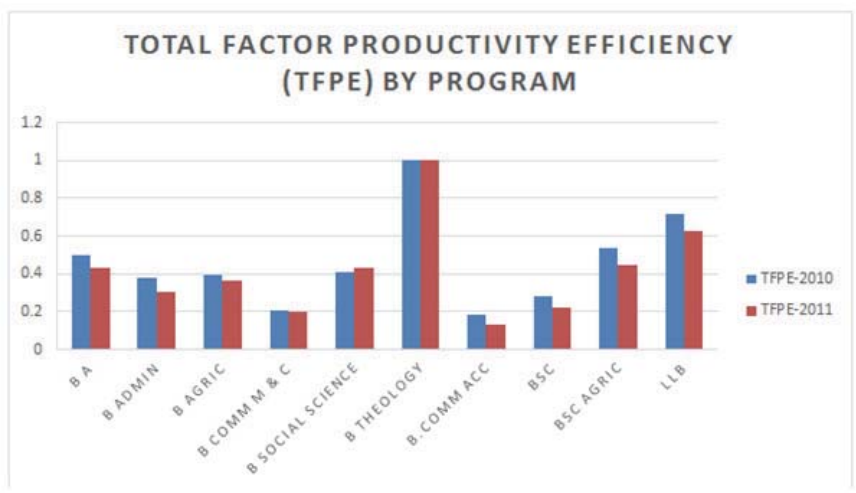

Figure 3: Total Factor Productivity Efficiency (TFPE) of programmes

Overall, there is decrease in the efficiency of programmes in the 2011 period except for Social Science which showed a slight improvement and Theology which remained constant. Theology and Law had high efficiencies of 100\% and 60\%, respectively. The Bachelor of Commerce (Management) and Bachelor of Commerce (Accounting) programmes had low efficiencies that were slightly below $20 \%$.

When a closer look is made in each programme's efficiency, the gap to full efficiency can be revealed and the graphical presentation in figure 4 below, displays these efficiency gaps. The Bachelor of Theology had maximum possible efficiency score (0 deficiency). The Bachelor of Commerce (Management) together with Bachelor of Commerce (Accounting), had $79 \%$ and $81 \%$ deficiencies respectively, and had the largest efficiency gaps (deficiencies) to close over the same period of 2010 .

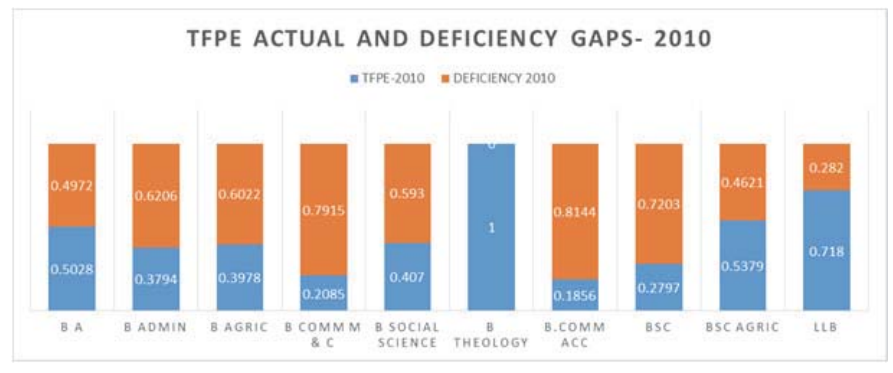

Figure 4: TFPE and deficiency gaps for 2010

On the other hand, the 2011 period, as shown in Figure 5 below, revealed a situation in which inefficiency gaps were increasing, except for Bachelor of Theology which maintained a full efficiency score of one with zero deficiency.

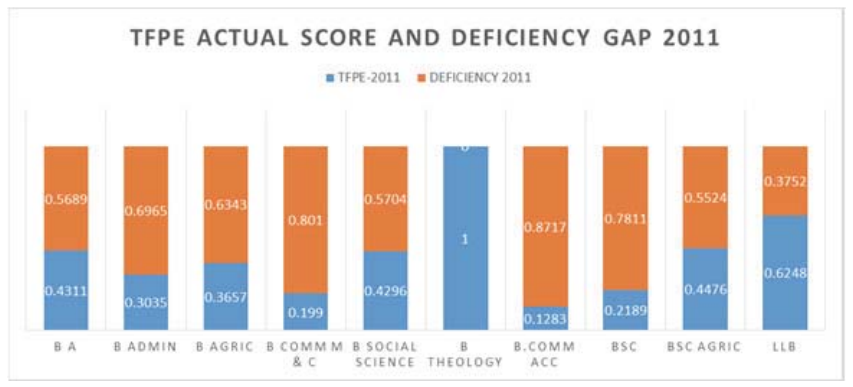

Figure 5: TFPE and deficiency gap for 2011 
Roughly checking at other forms of efficiencies in figures 6 and 7 below, such as the Output-based Technical Efficiency (OTE) and Output-based Scale Efficiency (OSE), the Bachelor of Theology still topped the list in terms of the best efficient programme. The least efficient over two years was Bachelor of Commerce in Accounting. Among the different forms of efficiencies, Output-based Scale Efficiency (OSE) dropped in 2011 as compared to 2010 figures. In 2010, four of the ten programmes had OSE scores below 0.5. However, in 2011 eight out of ten of the programmes had scores below 0.5 . These results suggest a decrease in efficiency as years into the programmes progress.

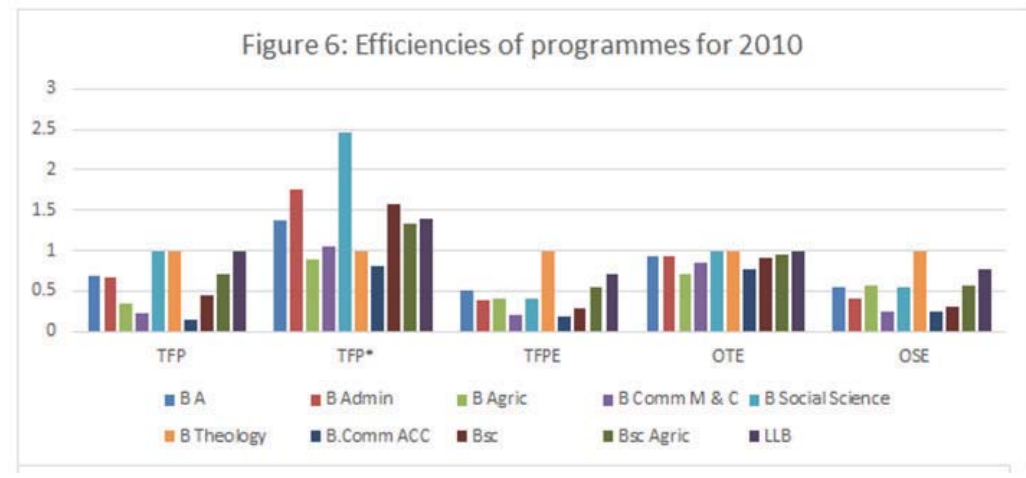

Figure 7: Efficiencies of programmes for 2011

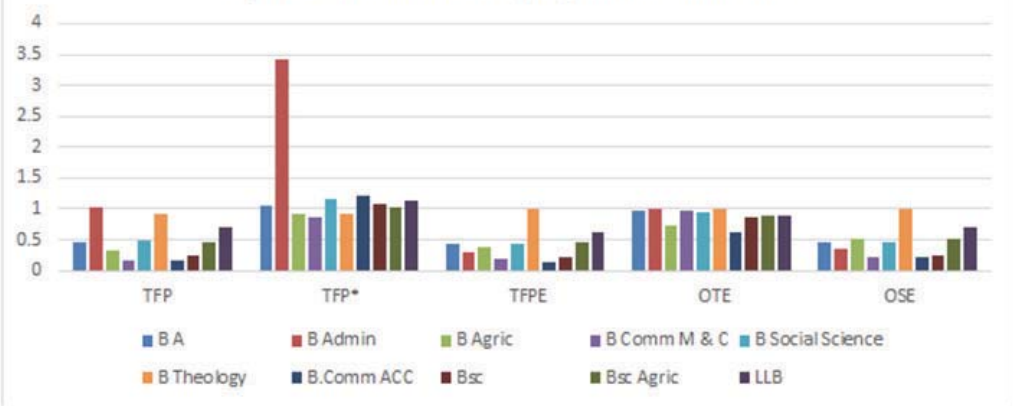

The following table displays all the calculated efficiencies including those discussed above and other relevant measures from both the input based and output based angles of efficiency.

\begin{tabular}{|c|c|c|c|c|c|c|c|c|c|c|c|c|c|c|c|c|}
\hline DegreeP & Period & TFP & TFP* & TFPE & OTE & OSE & OME & ROSE & OSME & ITE & ISE & IME & RISE & ISME & RME & \\
\hline $1 \mathrm{BA}$ & 2010 & 0.6939 & 1.38 & 0.5028 & 0.9211 & 0.5459 & 1 & 0.5459 & 0.5459 & 0.7534 & 0.6674 & 1 & 0.6674 & 0.6674 & 1 & \\
\hline $11 \mathrm{BA}$ & 2011 & 0.4591 & 1.0648 & 0.4311 & 0.9586 & 0.4498 & 1 & 0.4498 & 0.4498 & 0.4451 & 0.9686 & 1 & 0.9686 & 0.9686 & 1 & \\
\hline 2 B Admin & 2010 & 0.6639 & 1.75 & 0.3794 & 0.9321 & 0.407 & 1 & 0.407 & 0.407 & 0.7123 & 0.5326 & 1 & 0.5326 & 0.5326 & 1 & \\
\hline 12 B Admin & 2011 & 1.0345 & 3.4081 & 0.3035 & 1 & 0.3399 & 1 & 0.3035 & 0.3035 & 1 & 0.3399 & 1 & 0.3035 & 0.3035 & 0.8931 & \\
\hline 3 B Agric & 2010 & 0.3536 & 0.8889 & 0.3978 & 0.7072 & 0.5625 & 1 & 0.5625 & 0.5625 & 0.5 & 0.7956 & 1 & 0.7956 & 0.7956 & 1 & \\
\hline 13 B Agric & 2011 & 0.3352 & 0.9167 & 0.3657 & 0.7243 & 0.5049 & 1 & 0.5049 & 0.5049 & 0.5 & 0.7314 & 1 & 0.7314 & 0.7314 & 1 & \\
\hline 4 B Comm N & 2010 & 0.2181 & 1.0459 & 0.2085 & 0.8539 & 0.2442 & 1 & 0.2442 & 0.2442 & 0.2554 & 0.8164 & 1 & 0.8164 & 0.8164 & 1 & \\
\hline 14 B Comm N & 2011 & 0.174 & 0.8746 & 0.199 & 0.9758 & 0.2039 & 1 & 0.2039 & 0.2039 & 0.2 & 0.9949 & 1 & 0.9949 & 0.9949 & 1 & \\
\hline 5 B Social Sc & 2010 & 1 & 2.4568 & 0.407 & 1 & 0.5459 & 1 & 0.407 & 0.407 & 1 & 0.5459 & 1 & 0.407 & 0.407 & 0.7455 & \\
\hline 15 B Social Sc & 2011 & 0.4984 & 1.1601 & 0.4296 & 0.9553 & 0.4498 & 1 & 0.4498 & 0.4498 & 0.4451 & 0.9652 & 1 & 0.9652 & 0.9652 & 1 & \\
\hline 6 B Theolog & 2010 & 1 & 1 & 1 & 1 & 1 & 1 & 1 & 1 & 1 & 1 & 1 & 1 & 1 & 1 & 1 max \\
\hline 16 B Theolog & 2011 & 0.9224 & 0.9224 & 1 & 1 & 1 & 1 & 1 & 1 & 1 & 1 & 1 & 1 & 1 & 1 & 1 max \\
\hline 7 B.Comm A & 2010 & 0.152 & 0.8189 & 0.1856 & 0.76 & 0.2442 & 1 & 0.2442 & 0.2442 & 0.2 & 0.928 & 1 & 0.928 & 0.928 & 1 & \\
\hline 17 B.Comm A & 2011 & 0.1549 & 1.2077 & 0.1283 & 0.6289 & 0.2039 & 1 & 0.2039 & 0.2039 & 0.2 & 0.6413 & 1 & 0.6413 & 0.6413 & 1 & \\
\hline $8 \mathrm{Bsc}$ & 2010 & 0.4428 & 1.5835 & 0.2797 & 0.9161 & 0.3053 & 1 & 0.3053 & 0.3053 & 0.4834 & 0.5785 & 1 & 0.5785 & 0.5785 & 1 & \\
\hline $18 \mathrm{Bsc}$ & 2011 & 0.2334 & 1.0663 & 0.2189 & 0.8587 & 0.2549 & 1 & 0.2549 & 0.2549 & 0.25 & 0.8756 & 1 & 0.8756 & 0.8756 & 1 & \\
\hline 9 Bsc Agric & 2010 & 0.7136 & 1.3266 & 0.5379 & 0.9563 & 0.5625 & 1 & 0.5625 & 0.5625 & 0.7462 & 0.7208 & 1 & 0.7208 & 0.7208 & 1 & \\
\hline 19 Bsc Agric & 2011 & 0.4533 & 1.0128 & 0.4476 & 0.8865 & 0.5049 & 1 & 0.5049 & 0.5049 & 0.5 & 0.8952 & 1 & 0.8952 & 0.8952 & 1 & \\
\hline 10 LLB & 2010 & 1 & 1.3928 & 0.718 & 1 & 0.7626 & 1 & 0.718 & 0.718 & 1 & 0.7626 & 1 & 0.718 & 0.718 & 0.9415 & \\
\hline 20 LLB & 2011 & 0.701 & 1.1221 & 0.6248 & 0.8813 & 0.7089 & 1 & 0.7089 & 0.7089 & 0.7065 & 0.8843 & 1 & 0.8843 & 0.8843 & 1 & \\
\hline
\end{tabular}

Table 2: DEA Results by Degree Programme 
For example, the BA's TFPE of 0.50 tells us that the productivity of the BA's programme is $50 \%$ less than the maximum productivity that is possible using the resources available in 2010 (period 1), and 57\% less than the maximum possible in 2011 (period 2). The finding that, OTE of 0.92 OSE of 0.54 tells us that productivity shortfall is due to chiefly scale inefficiencies. More comparisons of the efficiencies of these programmes are displayed in the bar graphs above.

When inspecting the Returns to Scale (RTS) (see figure 8 below), that is, which part of the efficient frontier the programme is falling under, it revealed that B. Soc Science (0) fell under Constant returns to scale (CRS), and all the other programmes (1), fell under Increasing Returns to Scale (IRS). The understanding of returns to scale helps in understanding what happens when all the inputs are increased by a multiplier of $\mathrm{m}$. Increasing Returns to Scale (RTS) means that when inputs are increased by $\mathrm{m}$, output increases by more than $\mathrm{m}$. Constant Returns to Scale means that when inputs are increased by $\mathrm{m}$, then output increases exactly by $\mathrm{m}$. Decreasing Returns to Scale denotes that when inputs are increased by $\mathrm{m}$, our output increases by less than $\mathrm{m}$. The results presented below show that there is incentive to increase inputs as output will increase by more than the input multiplier, except for the B Soc Science programme where the output will increase by exactly the same multiplier as the input.

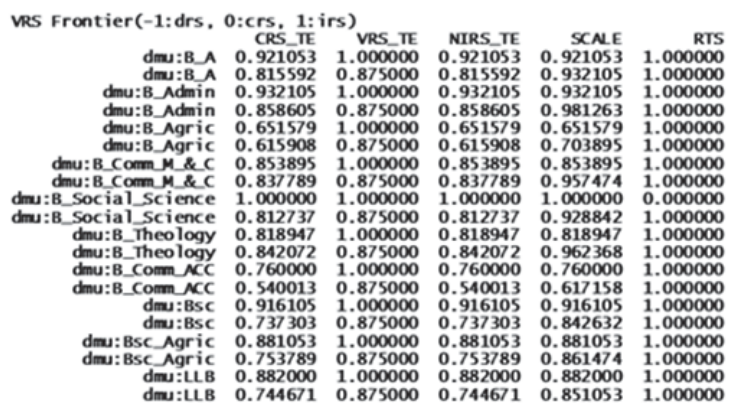

Figure 8: Returns to Scale

Also, it is imperative to note here that after checking for slackness in any of the inputs and outputs, no slack was found. This means that all inputs can be increased and the efficiency of programmes improved in the process.

\subsection{The predictors of efficiency in Foundation Provisioning programmes of the various Faculties.}

Below, is figure 9 which shows the regression model computed to ascertain predictors of efficiency in the foundation Provisioning programmes of the various faculties.

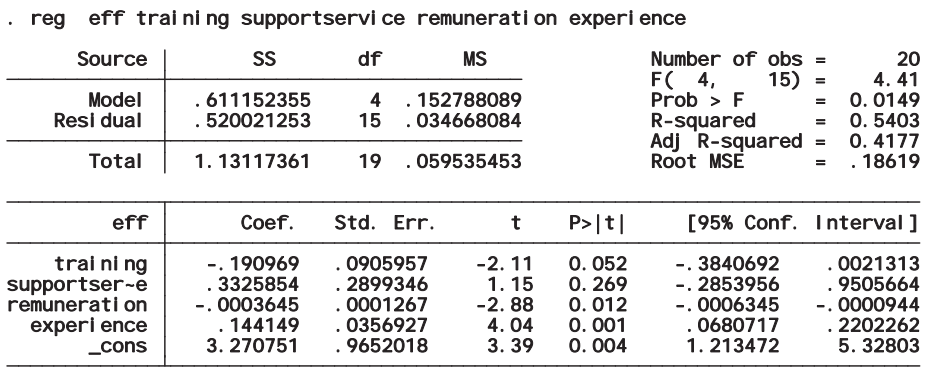

Figure 9: Regression Model for the predictors of foundation provisioning efficiency

From this model, the experience of running a foundation programme (0.001) and remuneration $(0.012)$, explain positively the predictors of efficiency in all four Faculties. Training workshops for lecturers and Supplemental Instruction (SI) support to foundation students were not significant. The model shows that over $54 \%\left(R^{2}=0.5403\right)$ of the variations in the efficiency scores in foundation programmes in the selected university are explained by the controlled variables, namely: training, SI, remuneration and experience of running the programme. It was of interest to check how the results appear 
after controlling for random effects. Using General Least Squares method, we learnt that $54 \%$ of the between programme variations can be explained by the model, and up to $60 \%$ of the within programme variations. A Prob $>\mathrm{Chi}^{2}$ of 0.000 provides confidence of the fitness of the model, at $5 \%$ significance level.

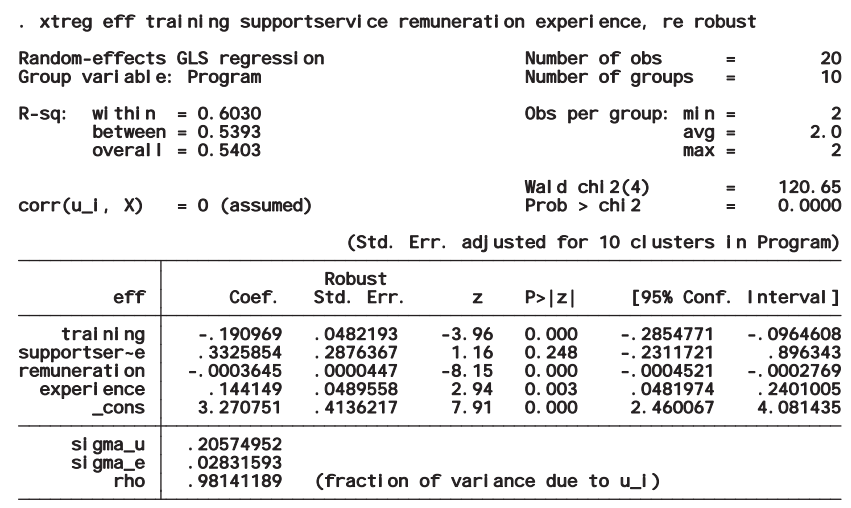

Figure 10: Regression model for between programmes

\subsection{Foundation Provisioning efficiency and academic success in main stream}

To determine whether programme efficiency is related to academic success, prediction analysis was carried out and the graphical results are shown in figure 11 below.

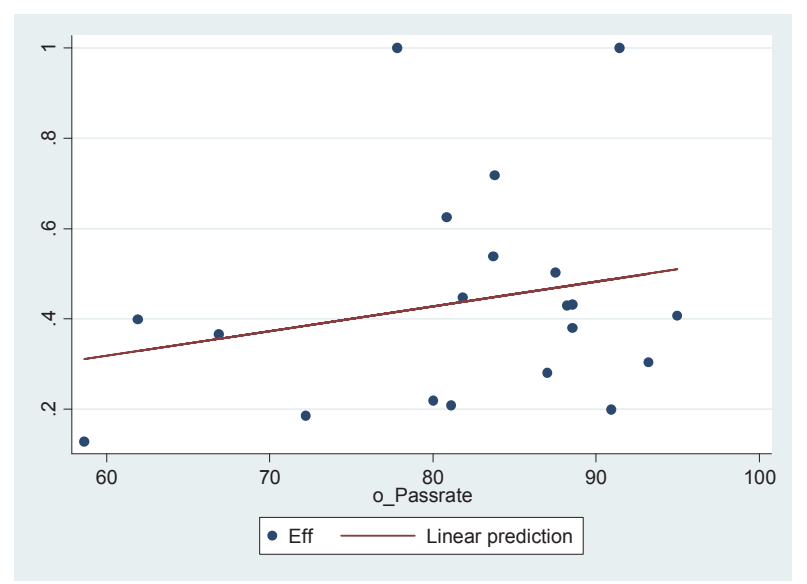

Figure 11: Linear prediction of efficiency and mainstream academic success

Though the relationship is weak, the results suggest that efficiency of programmes significantly predicts pass rates in the mainstream. This means that the programmess with higher efficiency scores $(0.7-1)$ had high pass rates for their students in the mainstream ranging between 80 and 90 percent. Also, the programmes with low efficiencies (0.2-0.4) had pass rates below $50 \%$. There are however, programmes that had high pass rates even though they had low efficiency scores.

\section{Discussion}

The method of studying educational efficiency employed is based on a longitudinal analysis of a cohort of students' data as did other studies such as Tattersal, Waterink, Hoppener, and Koper (2006). The use of Data Envelopment Analysis 
(DEA) as the primary method for analysing the efficiency of educational programmes finds support from other studies of efficiency of schools systems (Carter, 2012; Giminez, Prior, and Thieme, 2007; Jeon and Shields, 2003) that state the importance of using DEA models when studying efficiency at both institutional and programme levels. Caution should be exercised when looking at the overall efficiency level of foundation provisioning institutionally which is at $44 \%$. This is because of what Cooze (1991) refers to as the myriad of factors that impinge upon students' achievement, an outcome variable in efficiency studies in the education sector. These factors were not captures in the model for this particular study.

The findings of this research on the bearing that remuneration levels have on efficiency are consistent with Badri and Mourad (2012) who found that cost per teacher was an input variable that had the greatest impact on the efficiency levels of schools. However, in a study by Carter (2012) the average teacher base salaries were found to be ineffective in predicting efficiency. Since the years of experience of running foundation have a significant bearing on the efficiency for this particular study, a consideration for the sharing of "good practices" in the operations of Faculties and programmes would benefit foundation provisioning institutionally (Badri and Mourad, 2012). Most studies on educational efficiency have not considered this aspect, except for those studies that looked at years of teaching experience. For example, in Carter (2012) teachers' average years of experience shows statistically significant effects on efficiency.

The presumed impact of expending resources on teaching development training workshops for foundation provisioning lecturers, and its bearing on students' learning outcomes, that is pass rates, did not seem to have any significant effect on efficiency. This could be attributed to the fact that the effects of professional development are difficult to observe and problematic when quantified and manipulated. Measuring efficiency with inputs that are problematic is captured in Jeon and Shields (2003) assertion that schools may manipulate practices and the curriculum to achieve better looking results rather than these being the results of developmental training workshops.

Again, the effects of support for students, in the form of Supplemental Instruction (SI) did not have any significant impact on efficiency. Perhaps, the voluntary nature of SI, and the fact that not all the foundation modules and students made use of SI accounts for this insignificance. The finding on the positive relationship between efficiency and pass rates suggests that improving the educational productivity through allocations, reallocations, and optimum utilisation of the input variable could lead to improve academic performance.

\section{Conclusions}

Generally, overall efficiency of Foundation Provisioning in a selected Higher Education Institution is low at $44 \%$ with the majority of programmes falling below $50 \%$ in TFPE. Though the efficiency model used consisted of only four input variables and one output variable, we conclude that the efficiency model succeeded in explaining more than $56 \%$ of the variations in the efficiencies in foundation provisioning. The study concludes that there are variations in the efficiency levels of faculties and programmes and these are accounted for by the salary levels of foundation lecturers as well as the Faculty's experiences of running foundation provisioning. Though supplemental instruction and teaching development support were insignificant, they are important components of the input variables that warrant proper conceptualisation and operationalisation so that they are used to explain the efficiency levels of programmes and faculties. The positive relationship between efficiency at foundation and academic performance in the mainstream makes us to conclude that improving academic achievement in the mainstream requires the improvement of the efficiency levels of programmes and Faculties in the foundation/extended year. Therefore, if the university wants to improve pass rate of foundation students in main stream, improving efficiency of each programme is the starting point.

\section{Recommendations}

The study recommends research that will expand the model to include other input variables such as foundation lecturers' qualifications, class sizes in the modules, and years of experience in teaching foundation. As far as the outputs, we recommend that a similar study should be conducted that would look into the qualitative indicators of passes in the form of grades over and above the quantification of pass rates in the modules. At practice level, in the Faculties and programmes, the study recommends improvement of efficiency levels of programmes by altering the input variables or match resource allocation to the achievement of targets. This could be done by modifying the allocation of resources, reduction in the consumption of resources, and improving the management of resources to increase results, and decrease in the wastage of resources. 


\section{References}

Badri, M.A., \& Mourad, T. (2012). Determinants of School Efficiencies in Abu Dhabi Using

DEA. 2012 International Conference on Management and Education Innovation IPEDR. 37, 314-318.

Breier, M., \& Mabizela, M. (2008). Higher education. Kraak A \& Press K (eds), 278-299.

Boughey, C. (2005). Epistemological Access to the university: An Alternative perspective. South African Journal of Higher Education, 19 (3), 638-650.

Budget speech (2013) www.treasury.gov.za/documents/national\%20budget/2013/Carter, L. (2012). Data Envelope Analysis: Measurement of Educational Efficiency in Texas. Doctor of Education (Educational Administration), August 2012.

Cohen, L., Manion, L., \& Morrison, K. ( 2007). Research Methods in Education, (6 $6^{\text {th }}$ ed.). London. Routledge Taylor and Francis Group.

Cooze, J. (1991). The elusive concept of efficiency in education. http://www.mun.ca/educ/faculty/mwatch/vol1/cooze.html accessed13 August 2013-11-15.

Department of Education. (2001). National Plan for Higher Education. Pretoria: Department of Education.

Frith, V., \& Lloyd, P. (2013). Quantitative Literacy and Epistemological Access at University: Reflections on using the Threshold Concepts Framework for Research. Proceedings of the Seventh International Mathematics Education and Society Conference, 2, 272-281.

Gephart, R. (1999). Paradigms and Research Methods. Research Methods Forum. Vol. 4. Retrieved from http://division.aomomline.org/rm/1999_RMD_Forum_Paradigms_and_Research Methods.htm.

Giminez, V., Prior, D., \& Thieme, C. (2007). Technical efficiency, managerial efficiency and objective-setting in the educational system: an international comparison. Journal of the Operational Research Society. 58, 996-1007.

Jeon, Y., \& Shield, M.P. (2003). The Efficiency of Public Education In the Upper Peninsula of Michigan.

Levin, H.M., Jamison, D.T., \& Radner, R. (1976). Concepts of Economic Efficiency and Educational Production in Education as an Industry. http:// www.nber.org/http: nber.org/Bkks/jami76-1, 149-198.

Lewis, M.W., \& Grimes, A.J. (1999). Metatriangulation: Building theory from multiple paradigms. Academy of Management Review, 24 (4), $672-690$.

Lockheed, M.E. (1989). The measurement of educational efficiency and effectiveness. Paper presented at the Annual Meeting of the American Educational Research Association (New Orleans, LA, April 5-9, 1989).

Mancebon, M., \& Bandres, E. (1999). Efficiency evaluation in secondary schools: The key role of model specification and of ex post analysis of results. Education Economics, 7(2), 131 - 152.

Perelman, S., \& Santin, D. (2008). Measuring educational efficiency at student level with parametric stochastic distance functions: an application to Spanish PISA results.

Education Economics, 19(1), 29-49.

SAPA (2008). University dropouts increase. Available at:http://news.iafrica.com/sa/917608.htm [Accessed July 21, 2012].

Scott, I., Yeld, N., \& Hendry, J. (2007). Addressing diversity and development in South Africa: Challenges for educational expertise and scholarship. Cape Town: Council on Higher Education for the Improving Teaching and Learning for Success project. Unpublished.

Strydom, J. F., Mentz, M., \& Kuh, G. D. (2010). Enhancing success in higher education by measuring student engagement in South Africa. Acta Academica.

Tattersall, C., Waterink, W., Hoppener, P., \& Koper, R. (2006). A Case Study in the Measurement of Educational Efficiency in Open and Distance Learning, Distance Education. 27(3), 391- 404. 
